\title{
Title X Family Planning Program
}

\section{Overview}

The Family Planning Program was enacted in 1970 as Title $\mathrm{X}$ of the Public Health Service Act. It provides grants to public and nonprofit agencies for family planning services, research, and training. Administered by the U.S.

Department of Health and Human Services (HHS), it is the only domestic federal program devoted solely to family planning and related preventive health services.

What Is the Federal Funding Level? FY2015 funding is \$286.5 million, the same as the FY2014 level.

$\begin{array}{lr}\text { FY20I5 Appropriations: } & \$ 286.5 \text { million } \\ \text { Clients Served (20I3): } & 4.6 \text { million } \\ \text { Number of Title X Clinics (20I3): } & 4,168\end{array}$

What Clinical Services Are Provided? Clinical services provided through Title $\mathrm{X}$ include contraceptive services and supplies, natural family planning methods, sexually transmitted disease testing and treatment, HIV testing and prevention, cervical and breast cancer screening, preconception health services, pregnancy testing and counseling, condoms, sterilization services, basic infertility services, and other patient education and referrals. All services are confidential.

Does Title X Fund Abortions? By law, Title X funds may not be used for abortions. A grantee's abortion activities must be "separate and distinct" from its Title X project activities.

What Do Clients Pay? Priority for services is given to persons with family income at or below $100 \%$ of the federal poverty guideline (FPL), who may not be charged for care. Clients from families with income between $100 \%$ and $250 \% \mathrm{FPL}$ are charged on a sliding scale based on their ability to pay. Clients from families with income higher than $250 \%$ FPL are charged fees designed to recover the reasonable cost of providing services.

For unemancipated minors who request confidential services, eligibility for discounts is based on the minor's own income.
Figure I. Title X Clients, by Age

(2013)

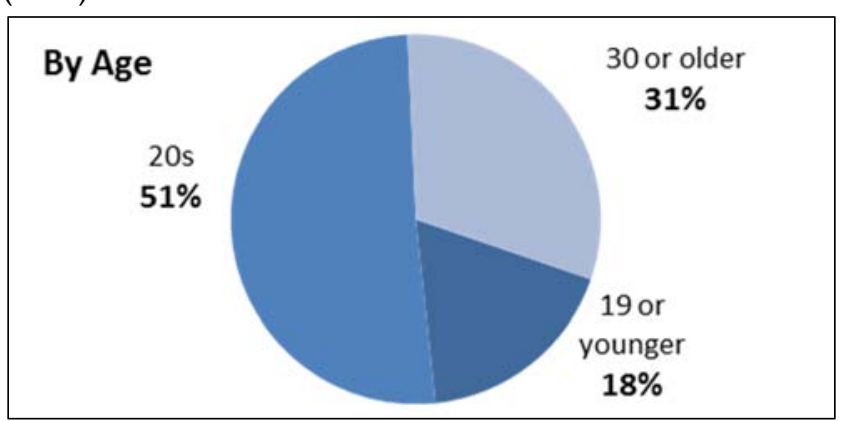

Source: U.S. Department of Health and Human Services (HHS), Title $X$ Family Planning Annual Report: 2013 National Summary, http://www.hhs.gov/opa/pdfs/fpar-2013-national-summary.pdf. Note: Sums may not total $100 \%$ due to rounding.

Figure 2. Title X Clients, by Race (2013)

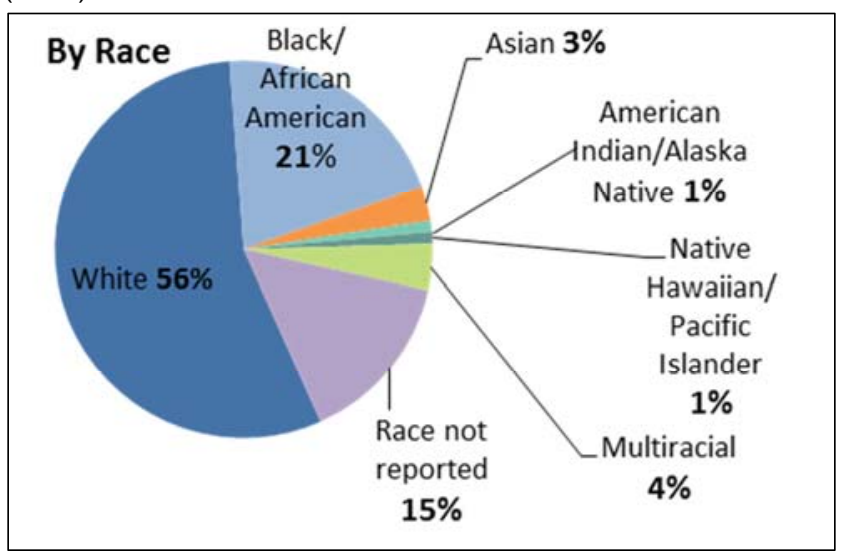

Source: HHS, Title X Family Planning Annual Report: 2013 National Summary, http://www.hhs.gov/opa/pdfs/fpar-20I3-nationalsummary.pdf.

Notes: $30 \%$ of clients (all races) identified as Latino/Hispanic. Sums may not total $100 \%$ due to rounding.

Who Are Title X Clients? In 2013, Title X-funded clinics served 4.6 million clients, primarily low-income women and adolescents. Of those clients, $92 \%$ were female, $8 \%$ were male, $70 \%$ had incomes at or below the FPL, and $90 \%$ had incomes at or below $200 \%$ FPL. For $61 \%$ of clients, Title X clinics are their "usual" or only regular source of health care. In 2013, 63\% of Title X clients were uninsured. 


\section{Other Family Planning Programs}

Do Other Federal Programs Fund Family Planning?

Although Title $\mathrm{X}$ is the only federal domestic program primarily focused on family planning, other programs also finance family planning, among their other services. These programs include Medicaid, the Health Center Program under Section 330 of the Public Health Service Act, Maternal and Child Health Block Grants, and Social Services Block Grants. In FY2010, Medicaid accounted for $75 \%$ of U.S. public family planning expenditures (including federal, state, and local government spending). In comparison, Title $\mathrm{X}$ accounted for $10 \%$.

Figure 3. Public Family Planning Expenditures by Funding Source, FY2010

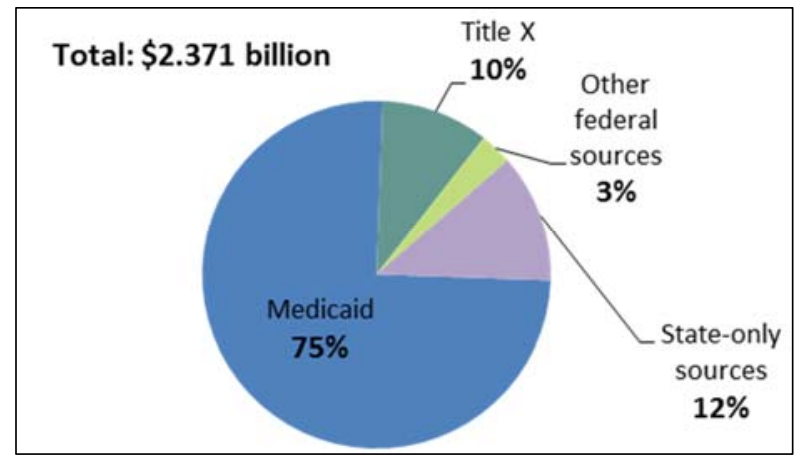

Source: Guttmacher Institute.

Are Private Health Plans Required to Cover Family Planning Services? Patient Protection and Affordable Care Act (ACA; P.L. 111-148, as amended) regulations and guidance require most non-grandfathered health plans to cover contraceptive services without cost-sharing. There are some exceptions and accommodations for religious objections.

Health plans in the ACA exchanges (marketplaces) are required to have a sufficient number and geographic distribution of "essential community providers," which include Title X projects.

\section{Supporting Views}

Health Benefits. Supporters argue that Title X prevents unintended and high-risk pregnancies, thereby preventing abortions and reducing fetal, infant, and maternal mortality and morbidity.

Cost-Effectiveness. Supporters see public family planning programs as cost-effective, saving money for public programs (such as Medicaid dollars that otherwise would be spent on prenatal, maternity, and newborn care).

Economic Benefits. Supporters contend that family planning, by allowing women to plan whether and when to have children, contributes to women's educational attainment, labor force participation, and financial independence.

\section{Opposing Views}

Funds to Abortion Providers. Opponents are concerned that some Title $\mathrm{X}$ funds go to abortion providers (such as some Planned Parenthood clinics). Although Title X funds may not be used for abortions, opponents argue that Title $\mathrm{X}$ funding frees up Planned Parenthood's other resources for its abortion activities.

Services to Adolescents. Opponents argue that by providing contraception to adolescents, the government is implicitly sanctioning nonmarital sexual activity among teens.

Confidentiality for Minors. Opponents are concerned that Title $\mathrm{X}$ projects do not require parental notification or parental consent for services to minors. Opponents contend that Title X confidentiality rules interfere with parents' rights to know of and guide their children's health care.

\section{Legislative Mandates}

The Consolidated and Further Continuing Appropriations Act, 2015 (P.L. 113-235) continues requirements for Title $\mathrm{X}$ funds included in previous years' appropriations laws:

- Title X funds may not be spent on abortions.

- All pregnancy counseling must be nondirective.

- Funds may not be spent on "any activity (including the publication or distribution of literature) that in any way tends to promote public support or opposition to any legislative proposal or candidate for public office."

- Grantees must certify that they encourage family participation when minors decide to seek family planning services.

- Grantees must certify that they counsel minors on how to resist attempted coercion into sexual activity.

- Family planning providers are not exempt from state notification and reporting laws on child abuse, child molestation, sexual abuse, rape, or incest.

The above requirements are in addition to statutory mandates in Title X of the Public Health Service Act, which, among other things, require family planning participation to be voluntary and prohibit the use of Title $X$ funds in programs in which abortion is a method of family planning.

\section{More Information}

For more information, see CRS Report RL33644, Title X (Public Health Service Act) Family Planning Program.

Angela Napili, anapili@crs.loc.gov, 7-0135 